\title{
The future European standard to determine odour in ambient air by using field inspection
}

\author{
J.M. Guillot*, I. Bilsen, R. Both, M. Hangartner, W.J Kost, W. Kunz, J. Nicolas, A. Oxbol, J. \\ Secanella, H. Van Belois, T. Van Elst, T. Van Harreveld
}

CEN/TC 264/WG 27

*Author : jean-michel.guillot@mines-ales.fr

\begin{abstract}
This paper presents the methodologies to determine odour in ambient air by field inspection that will be a new European standard. The objective is to characterize the odour in a defined area. Without making a link with potential annoyance due to the presence of odours, the described methods propose the way to characterize an exposed environment. Two approaches are defined in the new standard: the grid method and the plume method. The grid method can be used determine the exposure to ambient odours in a defined area of study, using direct observation of recognizable odours in the field by human panel members. This method must be applied over a sufficiently long period of time ( 6 or 12 months) to be representative for the meteorological conditions of that location. The result is the distribution of the frequency of exposure to odours within the assessment area. The plume method can be used to determine the extent of detectable and recognizable odours from a specific source using direct observation in the field by human panel members under specific meteorological conditions.
\end{abstract}

\section{Key words}

Odour, exposure, grid, plume, standardisation

\section{Introduction}

Odours at source can be characterized by dynamic olfactometry according to the European standard EN 13725 (2003). Such a method is not applicable for low odour levels like. This limit can depend on the olfactometer and also the baseline odour of the sampling bag that is used to collect odorous air. Typically, olfactometric values are never given for levels lower than 10 $\mathrm{ou}_{\mathrm{E}} / \mathrm{m}^{3}$ and generally theses lower values start in a range of 50 to $100 \mathrm{ou}_{\mathrm{E}} / \mathrm{m}^{3}$. The source characterizations with odour intensity allow the calculation of potential impact by using dispersion modelling. In case of low intensities, faint odours are recognized but cannot be measured by olfactometry. This case is very common in ambient air close to odorous activities (industrial plants, agricultural farms, WWTP...). In order to determine the odour in the field, the new standard describes methodologies to characterize odours in a defined area. Two methods are proposed in the new European standard: the grid and the plume method. In both cases, human panel members characterize in an area by the presence or not of an odour. Of course, human panel members use their sensory perception and only odour is followed and not global air pollution due to inodorous compounds. The first method (grid method) uses direct assessment of the ambient air by panellists to characterize odour exposure in a defined assessment area. Even if the presence of 
odours can be linked to annoyance with the contribution of other factors such as occurrence, the method is focused on odour exposure. The second method (plume method) uses panellists to determine the extent of the downwind odour plume, under defined meteorological conditions because the extent from a source is variable as a function of dispersion conditions. The extent of the recognisable plume can be used to estimate odour emissions, using reverse atmospheric dispersion modelling even if this part is not included in the method. If these methods are new for most European countries, some similar approaches were already used in Belgium, Netherlands or Germany. The German standards (VDI 3940 parts 1 and 2, 2006) are examples of such national standards.

For a link between odour exposure and annoyance (out of the scope of the future standard), it must be referred to studies that give some links for specific relationships (Steinheider and Winneke, 1993). Several countries were represented in the work group and experts that have participated to the elaboration of this standard are listed in table 1.

\section{I - Common recommendation for grid and plume methods}

The application of both grid and plume methods is the odour exposure, figure 1 gives a synthesis of odour measurement methods and their complementarity.

\section{I.1 Exclusions}

For both methods, this new European Standard does not include:

- the measurement of intensity of ambient odours

- the measurement of hedonic tone of ambient odours

- the calculation of estimated source emission rate from plume assessment (see Part 2 "Plume method") using reverse dispersion modelling

- a relation with odour annoyance

I.2 Organisation for field experiment and main criteria for panel selection

Because the panellist must be in the environment to smell, quality assurance of the experiment is controlled by a measurement leader. The global organisation is synthesized in figure 2 with the description of main roles for all participants. The field observations coordinator (with large experience of panel member) can be the same person as the measurement leader and can also participate as a panel member in the observations for the current measurement. The panel members shall be at least 16 years of age. The initial selection is carried out according to EN 13725 and panel members have to be checked at least every six months. Valid observations shall only be carried out by experienced panel members. To become an experienced panel member a panel member shall participate at least 5 times in a measurement cycle with at least 3 different odour types.

\section{II - Description of grid method}

The grid method determines the level of exposure to ambient odours in a defined area of study, using direct observation of recognisable odours in the field by human panel members.

The primary application of this standard is to provide a common basis for evaluation of exposure to ambient odours in the member states of the European Union. The field of application of this type of measurement is to characterise the level of odour exposure within the study area, in order to assess whether the impact of that exposure on resident population could be a justified cause for annoyance, using exposure criteria. The unit of measurement is the frequency of odour hours for 
an assessment square defined by four measurement points as a representative value for odour exposure for local conditions, e.g. local odour sources and the meteorology of that location.

II. 1 Principle of the grid method

The grid method is a statistical survey method which is applied over a sufficiently long period, to provide a representative map of the exposure to recognisable odour, as spatially distributed over the assessment area. These grid measurements are used to determine the distribution of the odour hour frequency for recognisable odours in ambient air in an assessment area under meteorological conditions that are assumed to be representative for the local meteorology (i.e. the last ten years). The odour hour frequency is an odour exposure indicator, and can be used to assess the exposure to recognisable odour originating from one or many specific odour source(s) emitting in a particular area of study. The odour hour frequency is determined for one or more assessment squares, configured as a grid of measurement points. An example is given in Figure 3.

The odour hour frequency for an assessment square is determined by making repeated single measurements by human panel members at the measurement points that define the corners of the assessment square. Each measurement point is measured repeatedly, 26 times at regular intervals over a one year field survey duration. One single measurement results in the test result 'odour hour' or 'non-odour hour'. By summing up the total number of odour hour test results for the four points defining an assessment square, divided by the total number of single measurements conducted at these four measurement points, the odour hour frequency for the assessment square is calculated. This principle is shown in schematic form in Figure 4.

One single measurement is conducted to determine whether the test result is an 'odour hour' or not. The measurement is conducted by having a human panel member inhale ambient air and smell its odour at 10 second timed intervals, for a total of measurement duration of 10 minutes. In this way 60 individual observations are obtained. Each observation consist of an indication of the presence or absence of odour and if an odour is recognised, the odour type.

If a particular odour type reaches or exceeds a percentage odour time of $10 \%$ (i.e. in six or more out of 60 observations), the result is classified as 'odour hour'. This implies that in theory the measurement can result in an 'odour hour' for more than one odour type, although this is rare. The limit of six to determine the 'odour hour' classification is set by convention.

This provides a map of exposure to a recognisable odour, expressed as odour hour frequency, for a grid of assessment squares. A typical representation of the result for the assessments squares is shown in Figure 5.

II. 2 Field survey of the grid method

The main points of the survey are listed in this paragraph.

Assessing odour type in the field

Panel members must have a map or plan with clearly marked measurement points and routes. Single measurement

A single measurement is the measurement of odour exposure by a panel member at one measurement point with a measurement duration of ten minutes (as in VDI 3940 part-1). The panel member sniffs the air every ten seconds and records the identified odour type or the absence of odour on a special data record sheet. At the end of the ten-minute interval, the panel member has assessed 60 observations. The panel member has to examine the ambient air for clearly recognizable odours (according to a list of odour types). The odour is clearly recognized when an odour type or quality can be clearly assigned to it. 
Assessment area, assessment squares and measurement points

The assessment area is defined before the start of measurement.

The assessment area is covered with a grid of equidistant points. The squares resulting from the joining together of four points are the assessment squares. Assessment squares are only necessary where odour exposure is to be measured on the basis of the study purpose. To reflect the decrease in odour exposure with increasing distance, adjacent assessment squares at different distances from the emitter should always be defined.

A square size of $250 \mathrm{~m}$ should initially be chosen. Depending on the needs in the particular case, larger (500 m maximum) and smaller squares (e.g. 125, 100 or $50 \mathrm{~m}$ ) are possible.

Survey duration and survey scale

The recommended survey duration is twelve months with a survey scale of 104 single measurements for each assessment square (26 single measurements for each measurement point). A shorter survey duration can be planned, for practical reasons, but the survey duration shall be at six months, with a minimum of 52 single measurements for each assessment square (13 measurements for each measurement point). If the survey duration is six months, the colder and warmer months shall be equally well represented. Within the survey duration, the single measurements to determine the odour exposure are carried out at the measurement points of the grid.

Survey schedule

Field surveys have to be scheduled so that the single measurements at the measurement points of an assessment square are independent of each other. This is deemed by convention to be the case if they are carried out on different days and no adjacent measurement points of a single assessment square are inspected per measurement round. To ensure the representativity of the survey, the specific field inspection dates should be chosen systematically before the start of the survey and not randomly. The measurement days have to be planned so that the season, the time of the week and the time of day are equally distributed. This means in particular that measurements have also to be carried out on Sundays and public holidays and at night.

Accompanying meteorological measurements

Grid measurement is a statistical survey method that supplies the odour hour frequency according to a systematic measurement plan. The planning and conduction of the measurements are carried out independently from expected or prevailing meteorological conditions (e.g. wind direction). Therefore the results of grid measurements are primarily valid only for the measurement period on which they are based and, because of variations in the meteorology during measurements cannot necessarily be applied to other measurement periods.

Accompanying meteorological measurements are therefore necessary if the result should be considered as representative for longer periods. The representativity of a meteorological wind measurement is always composed of two forms of representativity: Temporal and Spatial.

Plausibility check

For positive single measurements where an odour hour was determined a plausibility check is carried out. These positive single measurement results have to be compared to the direction of the wind during that measurement duration. For this, the current wind direction from the spatial representative weather station is considered with a sector of $\pm 60^{\circ}$ from the source (averaging period for wind measurement at least $10 \mathrm{~min}$ ). If the measurement point is within this sector and if the wind velocity is $>1 \mathrm{~m} / \mathrm{s}$, the positive result odour hour can be considered plausible. At calms 
of up to $1 \mathrm{~m} / \mathrm{s}$, it is assumed however that odour hour is plausible even if the measurement point is located outside the angle of the plume.

If the panel member's location is outside the above-mentioned plume angle, it is essential to check whether other sources or recirculation might be responsible for the measurement result. Implausible measurement results must be marked and recorded under "Miscellaneous odours". They are not included in the calculation of the odour hour frequency referring to the installation under investigation.

\section{III - Description of plume method}

This European Standard describes the Plume Method for determining the extent of detectable and recognisable odours from a specific source using direct observation in the field by human panel members under specific meteorological conditions.

With the plume method the presence or absence (YES/NO) of recognisable odours in and around the plume originating from a specific odour emission source, under a specified emission situation and meteorological conditions (specific wind direction, wind speed and boundary layer turbulence) is determined. The unit of measurement is the presence or absence of recognisable odours at a particular downwind location. The extent of the plume is assessed as the transition of absence to presence of recognisable odour.

The primary application of this standard is to provide a common basis for the determination of the plume extent in the member states of the European Union.

The results are typically used to determine a plausible extent of potential exposure to recognisable odours, or to estimate the total emission rate using reverse dispersion modelling.

The plume method includes two approaches (the stationary and the dynamic method) that are described in the following parameters.

III.1 Stationary plume method

The principle of the stationary plume method is illustrated in figure 6. A measurement cycle shall consist of at least 20 single measurements (4 intersection lines each consisting 5 single measurement points), from which at least 6 transition points (absence to presence) can be determined.

The maximum plume reach estimate shall be determined from observations obtained from two intersection lines, one of which including at least one odour presence point observation, and another intersection line where only odour absence point observations are recorded.

The distance between the intersection line without odour presence point observations and the nearest intersection line with odour presence point observation(s) shall be less than $20 \%$ of the maximum odour plume reach as determined from these observations.

At least 4 transition points (absence to presence), 2 at either side of the plume, shall be recorded in the total of intersection lines at distances along the plume direction between $30 \%$ and $70 \%$ of the maximum odour plume reach.

III.2 Dynamic plume method

The principle of the stationary plume method is illustrated in figure 7. A measurement cycle shall be conducted by at least two experienced panel members who each contribute approximately equal shares of the single measurement results.

A measurement cycle shall consist of at least 40 single measurements, from which at least 20 transition points (absence to presence) can be determined. 
The maximum plume reach estimate shall be determined from observations obtained during two crossings, one of which including at least one odour presence point observation, and another crossing where only odour absence point observations are recorded.

The distance between the crossing without odour presence point observations and the nearest crossing with odour presence point observation(s) shall be less than $20 \%$ of the maximum odour plume reach as determined from these observations.

At least 8 transition points (absence to presence), 4 at either side of the plume, shall be recorded at distances along the plume direction between $30 \%$ and $70 \%$ of the maximum odour plume reach.

\section{Conclusion}

This new standard with two methods gives the methodology to measure the odour exposure in the field. The grid method characterizes odour exposure in a defined assessment area. So, this first method is typically a way to give a frequency of odour exposure with 12 months of observation (6 months in particular cases). The plume determines the extent of the downwind odour plume, under defined meteorological conditions. So, this second method is typically a way to measure the impacted area under a selected meteorological condition. Because the standard describes methodologies, it doesn't give a result in terms of annoyance because the link between odour exposure and annoyance implies psychological aspects that cannot be characterized easily.

\section{References}

EN13725 (2003), Air quality - Determination of odour concentration by dynamic olfactometry. Published by CEN

Steinheider B. and Winneke G. (1993), Industrial odours as environmental stressors: Exposureannoyance associations and their modification by coping, age and perceived health, Journal of Environmental Psychology, 13, 353-363.

VDI Guideline 3940-Part 1 (2006), Measurement of odour impact by field inspection Measurement of the impact frequency of recognizable odours - Grid measurement

VDI Guideline 3940-Part 2 (2006), Measurement of odour impact by field inspection Measurement of the impact frequency of recognizable odours - Plume measurement 
Table 1: Members and Experts that participated, over the last 5 years, of the work Group and relative countries

\begin{tabular}{|c|c|c|}
\hline $\begin{array}{l}\text { BILSEN Ilse } \\
\text { BOONAERT Christophe } \\
\text { NICOLAS Jacques } \\
\text { VAN ELST Toon }\end{array}$ & & Belgium \\
\hline OXBOL Arne & & Denmark \\
\hline $\begin{array}{l}\text { GUILLOT Jean-Michel } \\
\text { KUNZ Wolfgang } \\
\text { NAJEAN Philippe } \\
\text { RIBEIRO Nicolas }\end{array}$ & & France \\
\hline JONES Nick & & England \\
\hline $\begin{array}{l}\text { BOTH Ralf } \\
\text { KOST Werner-Jürgen } \\
\text { MULLER Franck } \\
\text { FRANZEN-REUTER Isabelle } \\
\text { PERSCHAU Nicol }\end{array}$ & $\begin{array}{l}\text { Convenor } \\
\text { Secretary } \\
\text { Secretary }\end{array}$ & Germany \\
\hline SECANELLA Jordi & & Spain \\
\hline HANGARTNER Markus & & Switzerland \\
\hline $\begin{array}{l}\text { BONGERS, Margrethe } \\
\text { MILAN Bianca } \\
\text { VAN BELOIS Hugo } \\
\text { VAN HARREVELD Ton }\end{array}$ & & The Netherlands \\
\hline
\end{tabular}




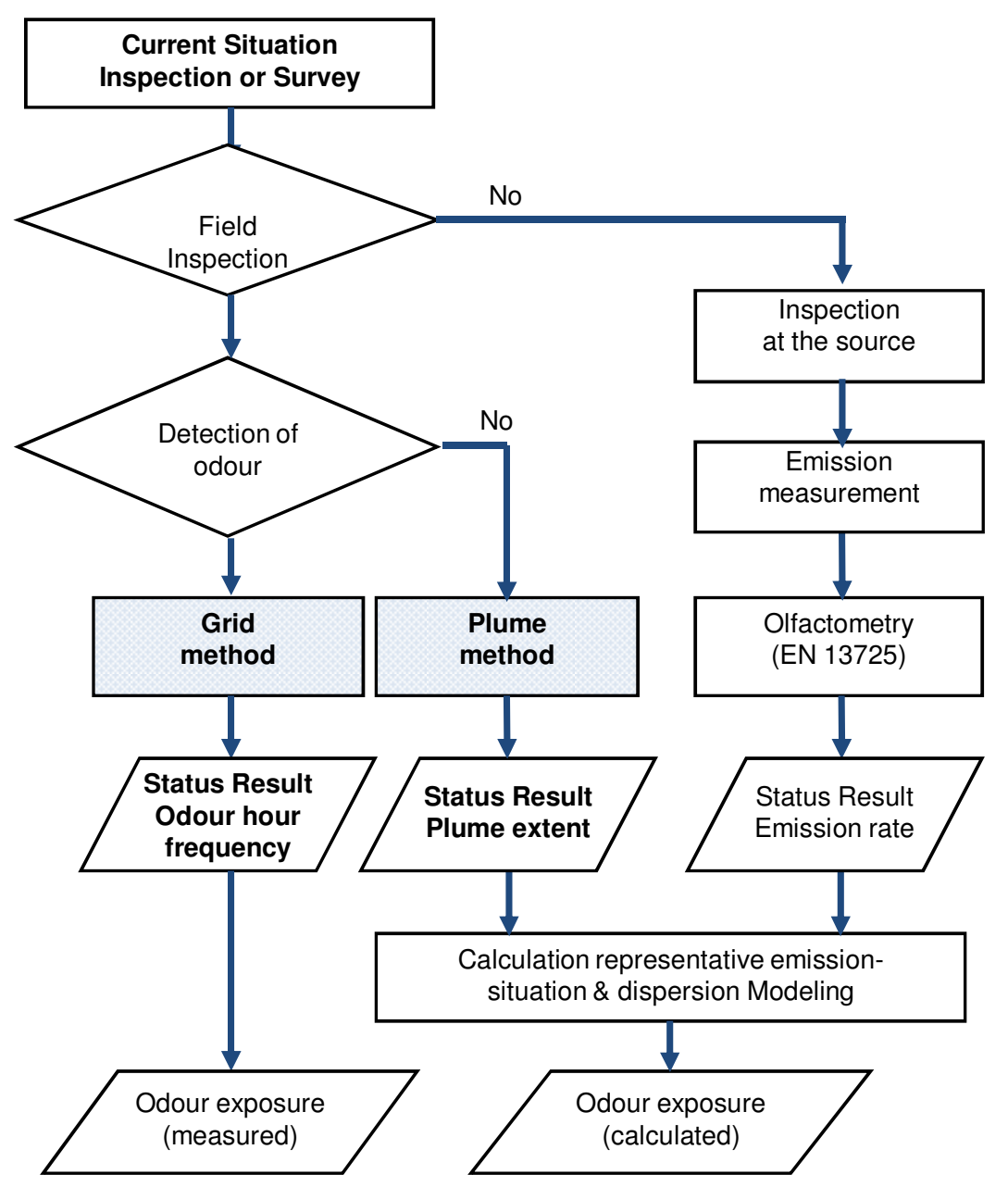

Figure 1: Global overview of odour measurement methods of the new standard (grid and plume method) and relationship with dynamic olfactometry according to EN 13725. 


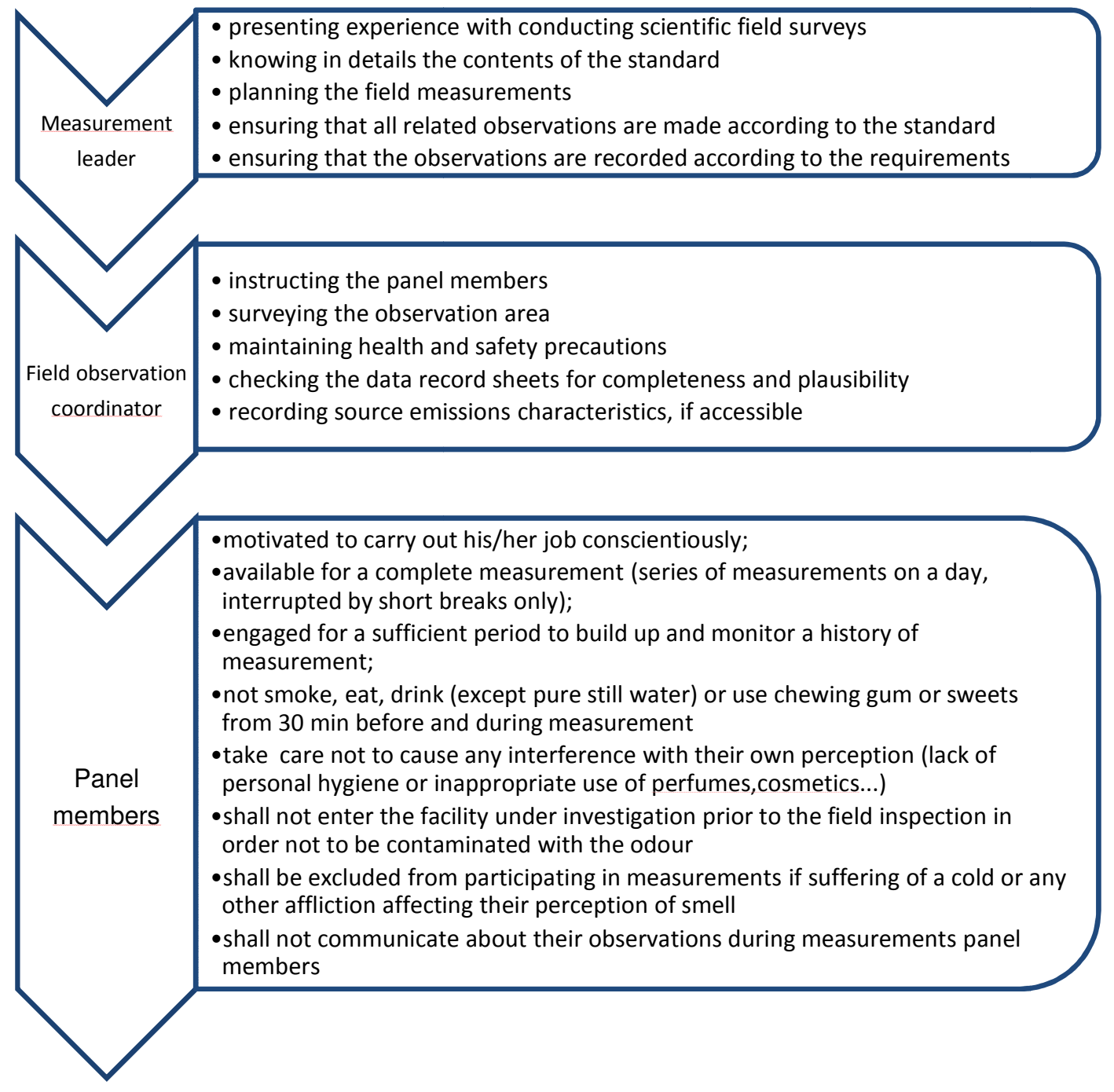

Figure 2: Organisation for field experiments. 


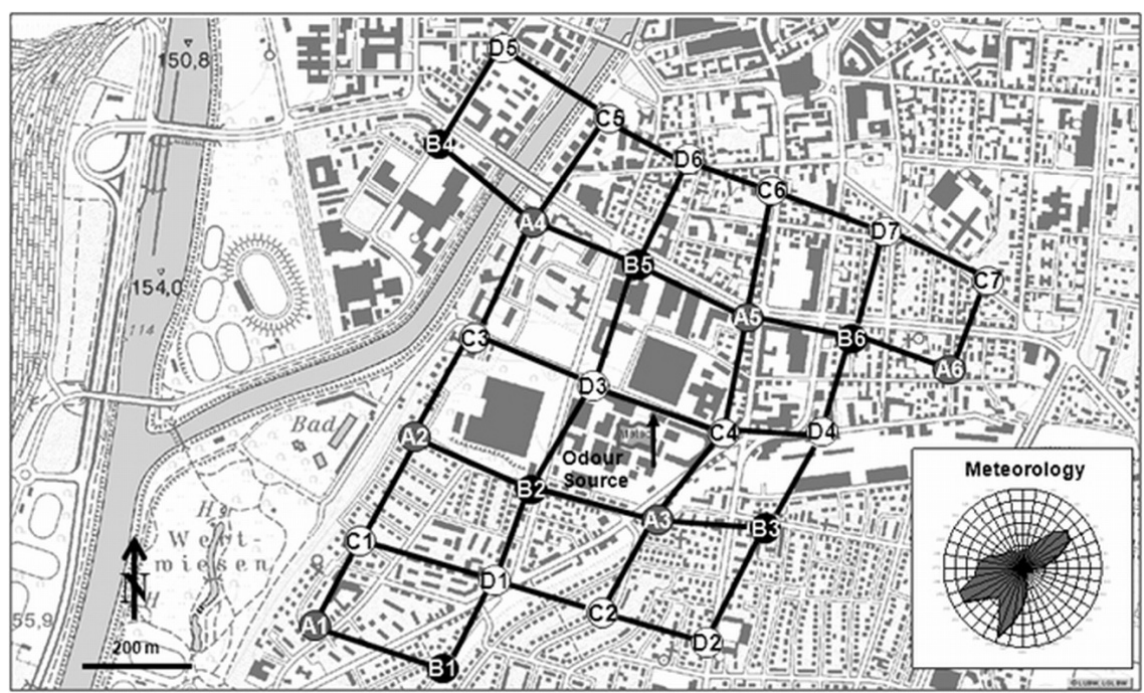

Figure 3: Position of the measurement points and of the assessment squares. Measurement round A consist of six measurement points: A1, A2, A3, A4, A5, A6; measurement round B consist of six measurement points: B1, B2, B3, B4, B5, B6; measurement round $\mathrm{C}$ consist of seven measurement points: $\mathrm{C} 1, \mathrm{C} 2, \mathrm{C} 3, \mathrm{C} 4, \mathrm{C} 5, \mathrm{C} 6, \mathrm{C} 7$; measurement round $\mathrm{D}$ consist of seven measurement points: D1, D2, D3, D4, D5, D6, D7.

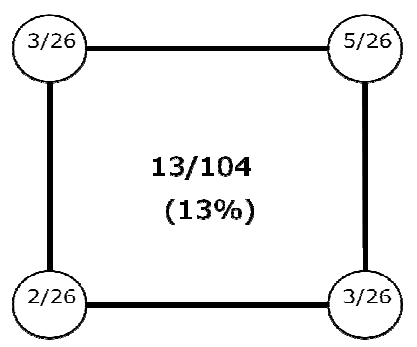

Figure 4: Schematic representation of the calculation of the odour hour frequency for an assessment square from the combined results obtained for the measurement points at the corners 


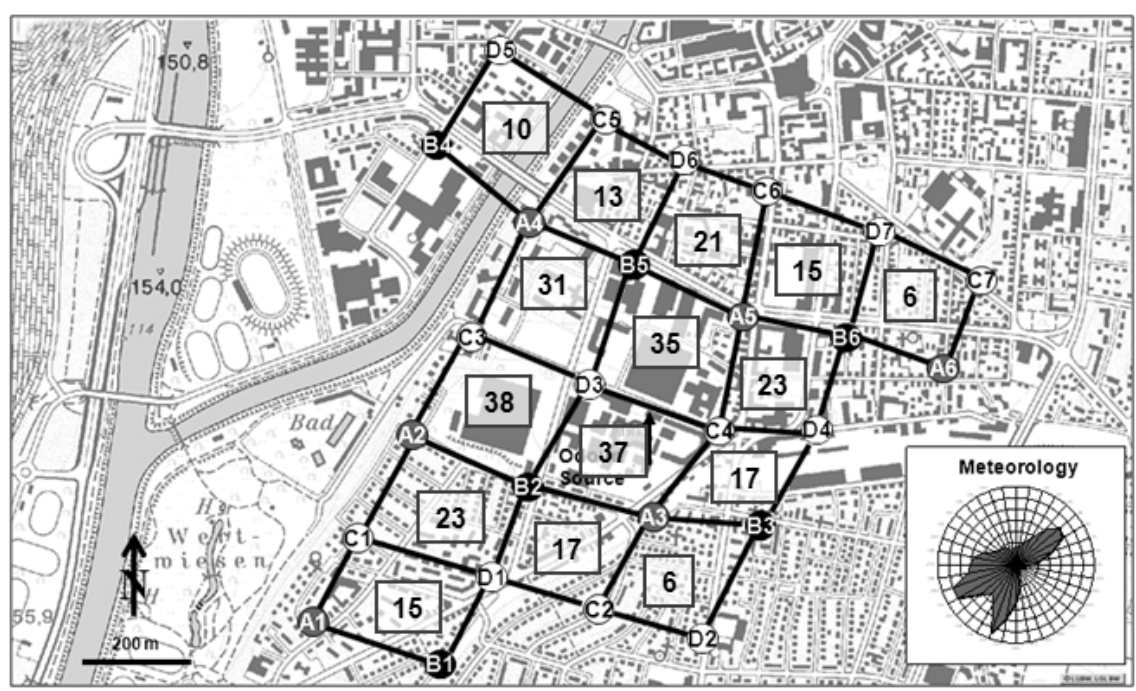

Figure 5: Measured values per assessment square expressed as odour hour frequency [\%] caused by the odour source under investigation (For details on evaluation of odour hours and odour hour frequencies per measurement point and assessment square see Annex G). 


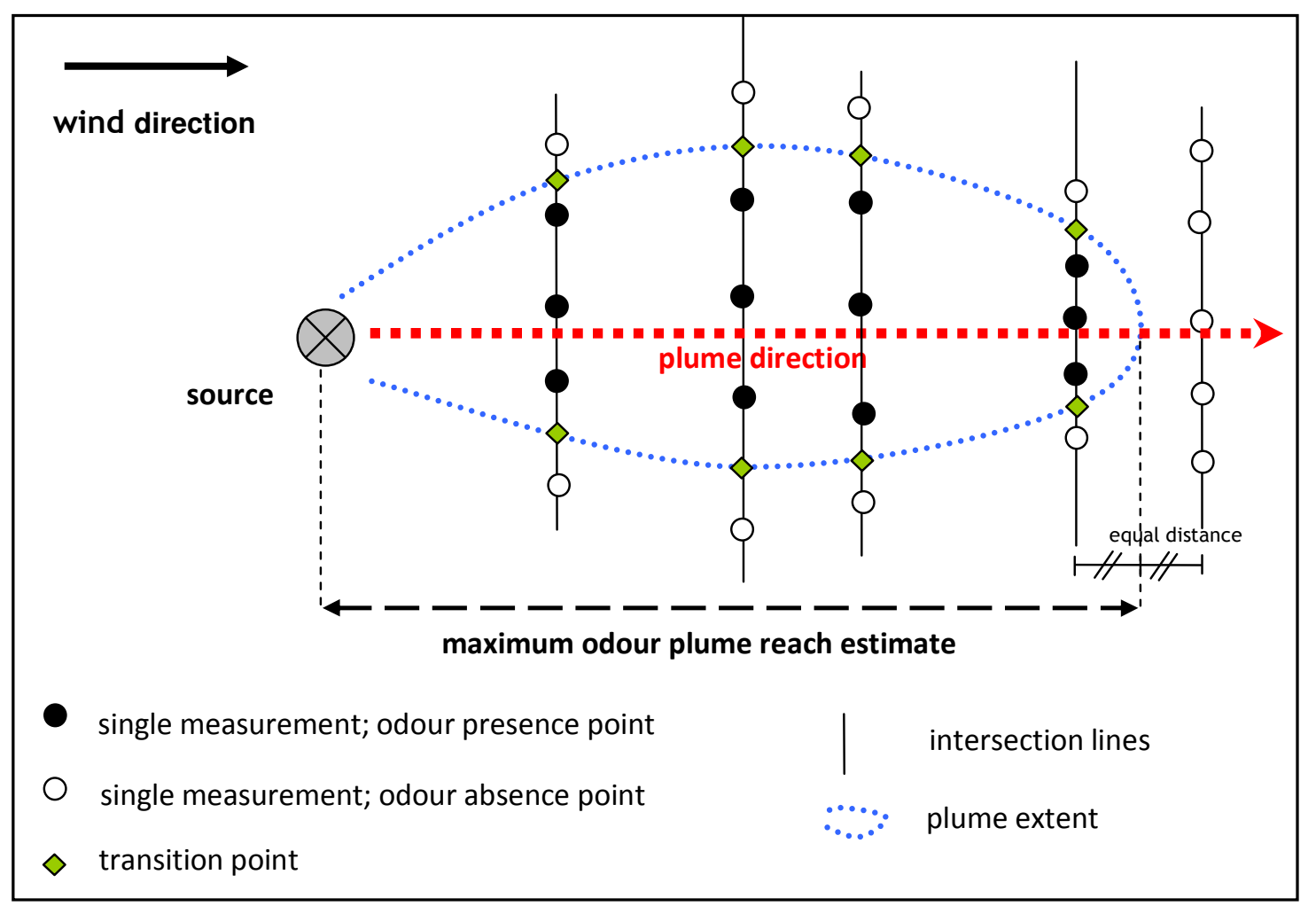

Figure 6: Schematic diagram of an example of stationary plume measurement

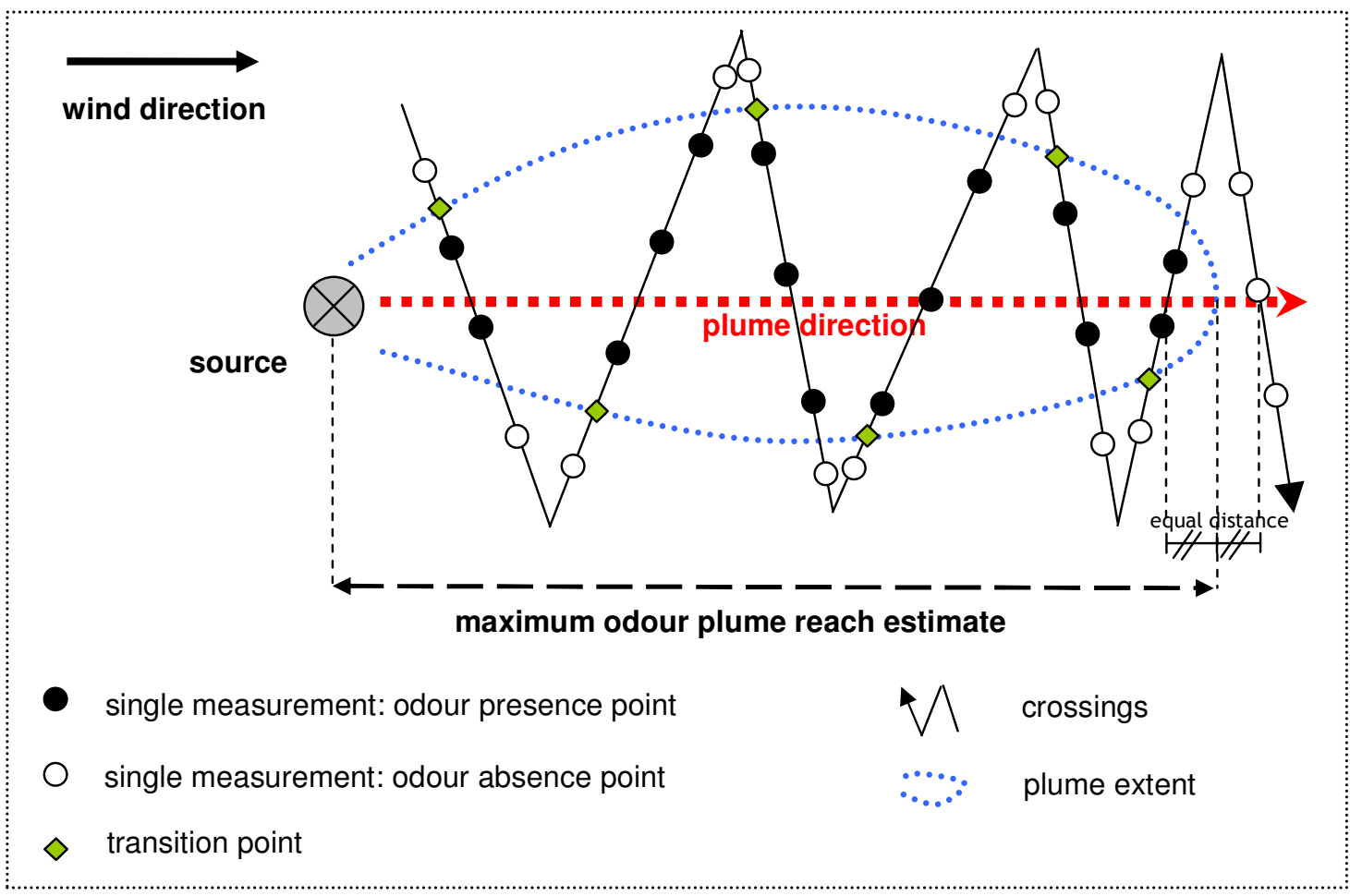

Figure 7: Schematic diagrams of an example of dynamic plume measurement (In this figure, the measurement is started from the source but can start going to the source) 